\title{
REGRESSÃO DE ÁREAS ÚMIDAS NA CHAPADA DO OESTE MINEIRO: MAPEAMENTO TEMPORAL DAS ÁREAS ÚMIDAS NO ALTO CURSO DO RIO UBERABINHA, MG E IMPACTOS AMBIENTAIS
}

\author{
Josimar dos Reis de Souza ${ }^{1}$
}

Lais Naiara Gonçalves dos Reis ${ }^{2}$

\section{RESUMO}

A partir do cenário atual observado no bioma Cerrado, de intensa utilização dos solos para a agropecuária e de problemas ambientais, este trabalho visou delimitar a regressão sofrida pelas áreas úmidas no Alto Curso da Bacia Hidrográfica do Uberabinha, Uberlândia (MG), nos anos de 1964 e 2009. Foram relacionadas às alterações sofridas pelo ambiente natural entre os dois períodos, trazendo estas questões ao debate dos impactos e conflitos provenientes das ações do Estado para a utilização dos solos do Cerrado. Para o mapeamento foi empregada a metodologia proposta por Novo (2008), utilizando fotografias aéreas de 1964 da USAF e imagens do satélite RapidEye de 2009. Os resultados apresentaram a redução das áreas úmidas em 38,08\% $\left(107,3 \mathrm{~km}^{2}\right)$. Observa-se, portanto, que as áreas preservadas na bacia hidrográfica estudada, ainda representam cerca de $20 \%$, por se tratarem de áreas úmidas, que mesmo com leis de proteção (APPs) sofrem pressão das monoculturas, principalmente nas áreas de contato agricultura-área úmida e muitas vezes continuam a ser drenadas em prol da expansão das áreas agrícolas, sendo necessária uma maior atenção dos órgãos de fiscalização.

PALAVRAS-CHAVE: Áreas Úmidas. Chapada do Oeste Mineiro. Impactos Ambientais.

\section{REGRESSION IN HUMID AREAS THE WEST MINER PLATEAU: TEMPORAL MAPPING OF HUMID AREAS IN THE UPPER COURSE OF THE UBERABINHA, MG AND ENVIRONMENTAL IMPACTS}

\begin{abstract}
From the present scenario observed in the Cerrado biome, the intense use of land for agricultural and environmental problems, this work aimed to delimit the regression suffered by humid areas in the Upper Course of

\footnotetext{
${ }^{1}$ Geógrafo e Mestrando em Geografia, Programa de Pós-Graduação em Geografia, Universidade Federal de Uberlândia (UFU). josimar.ig.geoufu@gmail.com.

${ }_{2}$ Mestre em Geografia, Doutoranda em Geografia, Programa de Pós-Graduação em Geografia, Universidade Federal de Uberlândia e Técnica em Sensoriamento Remoto, Instituto de Geografia, Universidade Federal de Uberlândia. lais ungida@hotmail.com.
} 
River Basin Uberabinha, Uberlandia (MG) in the years 1964 and 2009. Were related to the changes undergone by the natural environment between the two periods, bringing these issues to the discussion of impacts and conflicts arising from actions of the State for the use of the Cerrado soils. Was used for mapping the methodology proposed by Novo (2008), using aerial photographs from USAF of 1964 and images satellite from RapidEye of 2009. The results showed a reduction of humid areas in $38.08 \%\left(107.3 \mathrm{~km}^{2}\right)$. We observe, therefore, that the preserved areas in the watershed studied, it represents about 20\%, because they are humid areas, that even with protection laws (APPS) are under pressure of monocultures, especially in the areas of agriculture-humid areas contact continue to be drained towards the expansion of agricultural areas, greater attention of the supervisory board is required.

KEY-WORDS: Humid Areas. West Miner Plateau. Environmental Impacts.

\section{ÁREAS DE REGRESION EN HÚMEDO OESTE CHAPADA MINER: TIEMPO CARTOGRAFÍA DE LAS ZONAS HÚMEDAS EN ALTO RÍO CURSO UBERABINHA, MG E IMPACTOS AMBIENTALES}

De la situación actual observado en el bioma Cerrado, uso de la tierra para la agricultura intensa y los problemas ambientales, este trabajo tuvo como objetivodelimitar la regresión sufrida por los humedales en el curso superior del UberabinhaCuenca del Río, Uberlandia (MG), en los próximos años 1964 y 2009 estaban relacionados con los cambios experimentados por el entorno natural entre los dos períodos, con lo que estos temas para la discusión de los impactos y conflictos de lasacciones del Estado para el uso de los suelos del Cerrado. Para la cartografía se utilizó la metodología propuesta por Nueva (2008), el uso de fotografías aéreas de1964 USAF y 2009. Las imágenes de satélite RapidEye Los resultados mostraron una reducción de los humedales en el 38,08\% $\left(107,3 \mathrm{~km}^{2}\right)$. Tenga en cuenta, por tanto, que lasáreas preservadas en la cuenca estudiada, aún representan alrededor del 20\%, debido a que son los humedales, que incluso con las leyes de protección (PPAs), bajola presión de los monocultivos, en particular en las áreas de agricultura contactohumedales y, a menudo siguen siendo drenado hacia la expansión de las zonas agrícolas, y requieren una mayor atención de los órganos de control.

PALABRAS-CLAVE: Humedales. Chapada Minería West. Los impactos ambientales.

\section{INTRODUÇÃO}

A utilização dos potenciais do Bioma Cerrado nas últimas décadas (sobretudo a partir dos anos de 1960) ocorreu sobre áreas onde a cobertura vegetal nativa encontrava-se bem preservada. Essa ocupação foi marcada pela expansão dos reflorestamentos, das monoculturas de grãos e formação de pastagens destinadas à 
pecuária de alto rendimento (EMBRAPA, 2008). Estas ações acarretaram mudanças na ordem política, econômica e social, no que diz respeito principalmente aos contingentes populacionais que se deslocaram para áreas desse bioma; fruto das estratégias de ocupação desta parte do território nacional. Além disso, as implicações geradas pelo intenso uso antrópico gerou modificações do ecossistema natural, acarretando sérios problemas ambientais.

Até meados do século $X X$, a área de distribuição do Cerrado foi considerada secundária para a produção agrícola. A partir dos anos de 1960, com a transferência da capital federal do Rio de Janeiro para Brasília (localizada no "coração" da área de distribuição desse bioma), o interior brasileiro se tornou alvo da implantação de ampla rede de estradas e adoção das políticas de interiorização e de integração nacional, sendo a região inserida no contexto da produção de alimentos e de energia. $O$ Cerrado passou a se destacar na produção de grãos e abrigar grande parte do rebanho bovino do país. Com o desenvolvimento de tecnologias de produção, tornouse um dos mais importantes polos de produção de alimentos, contribuindo atualmente com mais de $25 \%$ da safra nacional de grãos, além de abrigar mais de $40 \%$ do rebanho bovino (ÁVIDOS; FERREIRA, 2007).

Apesar de serem incontestáveis os benefícios econômicos provenientes das atividades desenvolvidas nos solos do Cerrado, observou-se, em extensas áreas, o agravamento dos problemas ambientais, atingindo os variados extratos de ambientes naturais, com reflexos diretos e indiretos em áreas úmidas. Acerca disso Boaventura (2007) afirma que,

[...] a instalação e expansão de empreendimentos agropecuários, comumente desconsideraram a legislação relacionada ao meio ambiente e os princípios básicos de conservação, gerando, como consequência, excessiva fragmentação da cobertura vegetal nativa, a erosão do solo e o assoreamento dos cursos d'água. [...] Se uma parte das áreas do Cerrado foi ocupada por empreendimentos implantados seguindo as técnicas necessárias à obtenção de altas taxas de produtividade, outra parte, muito maior, foi abandonada, após ser desmatada, ou tem sido utilizada para o pastoreio extensivo, com rendimento extremamente baixo (BOAVENTURA, 2007, p. 194). 
As áreas úmidas são zonas de campos hidromórficos e constituem vales rasos com vertentes côncavas e trechos retilíneos de baixas declividades, cobertas por solos arenoso e fundo plano preenchido por solos argilosos, com elevada concentração de restos vegetais decompostos e elevados teores de carbono. São áreas de surgência gradual da água acumulada a pouca profundidade do solo. As áreas planas mais elevadas adjacentes constituem as zonas de infiltração e recarga, que captam a água de chuva e a transmitem para os lençóis subterrâneos. Em toda a extensão das áreas úmidas o lençol freático aflora ou está muito próximo da superfície. A importância primordial das áreas úmidas como recurso ambiental é o fato de serem produtoras e armazenadoras de água. São nascentes que deveriam permanecer intocadas, em benefício dos rios a que dão origem, e das comunidades bióticas que deles dependem (CASTRO JÚNIOR, 2002).

As áreas úmidas, estando distribuídas em relevos aplainados e fundos de vale são áreas que ficam expostas às consequências dos processos de degradação. Estudos realizados pela EMBRAPA (2008) apontam que,

\footnotetext{
Nas décadas de 1970 e 1980, grande número de empreendimentos, utilizando técnicas de drenagens e irrigação, foram implantados em áreas de veredas e em seu entorno, apoiados e incentivados por programas governamentais que os favoreciam com créditos facilitados, orientação técnica e, muitas vezes, com a disponibilização de equipamentos públicos. [...] Apesar desses programas terem sido interrompidos no final da década de 1980, é possível ainda hoje, identificar áreas onde tais intervenções foram e continuam a ser realizadas (EMBRAPA, 2008, p. 198).
}

A intensa exploração agropecuária tem despertado o interesse e preocupação com a qualidade do solo e sustentabilidade da exploração agrícola. O interesse em preservação dessas áreas se dá, sobretudo, por serem áreas "produtoras" de água e também pela grande concentração de Carbono nos solos, se constituindo como áreas de estoque de carbono, contribuindo assim com o equilíbrio das emissões de carbono, um dos principais gases do efeito estufa. Além disso, como as formações vegetais de áreas úmidas se desenvolvem nos vales onde a umidade é maior e as temperaturas mais amenas do que nas formações arbóreas do cerrado, esses 
ambientes funcionam como refúgios úmidos indispensáveis para a sobrevivência de grande parte das espécies da fauna (REDFORD; FONSECA, 1986).

A partir do cenário atual observado no bioma Cerrado e frente à ação ineficaz de proteção dos fragmentos de vegetação e sistemas naturais, este trabalho visou delimitar a regressão sofrida pelas áreas úmidas presentes em trechos da Chapada do Oeste Mineiro, nos anos de 1964 e 2009. Foram relacionadas às alterações sofridas pelo ambiente natural entre os dois períodos, trazendo estas questões ao debate dos impactos e conflitos inerentes ao uso/manejo dos solos e uso/gestão dos recursos hídricos.

A área foi escolhida, tendo em vista sua importância para o abastecimento público de parte dos habitantes de do município de Uberlândia (Minas Gerais). Por se tratar de uma bacia hidrográfica de importância regional para a irrigação das monoculturas existentes e para o abastecimento público, merece o aprofundamento dos estudos que permitam aos responsáveis pelas tomadas de decisões, adotar as melhores escolhas nos processo de organizar as intervenções econômicas, garantindo a possibilidade de conservação, preservação e recuperação de suas áreas.

\section{PROCEDIMENTOS METODOLÓGICOS}

\section{Características da área de estudo}

As Chapadas sedimentares do Oeste Mineiro, caracterizadas como superfícies residuais de aplainamento, concentram áreas úmidas expressivas. Particularmente na Chapada localizada entre os municípios de Uberlândia e Uberaba (MG), delimitada pela bacia hidrográfica do Alto Curso do Uberabinha em sua porção mais alta; está presente um mosaico paisagístico que reflete o sistema natural apresentado e intensa ocupação humana que alterou, e continua alterando, as zonas recobertas por solos com propriedades hidromórficas.

Trata-se de uma área que originalmente era toda coberta por Cerrado e que foi pioneira de desmatamento na região. Desde a década de 1970, a vegetação 
original do Cerrado que recobria toda a bacia foi substituída por extensas áreas de monoculturas (milho, soja, cana, etc.), pastagens e reflorestamento (BRITO, 2001).

O Alto Curso do Rio Uberabinha localiza-se no Estado de Minas Gerais, no Triângulo Mineiro, entre as coordenadas geográficas de 1856'00"S-19²6'00"S e $47^{\circ} 50^{\prime} 00^{\prime \prime O}-48^{\circ} 09^{\prime} 00^{\prime \prime O}$ (mapa 1). A área de sua drenagem abrange 728,43 km² com delimitação a partir do encontro com o Ribeirão Bom Jardim (jusante) até as áreas de nascentes no Ribeirão Beija-Flor (montante). Trata-se da rede de drenagem que alimenta o Rio Araguari, rio de domínio do Estado de Minas Gerais, afluente do rio Paranaíba, um dos formadores do Rio Paraná e portanto rio de domínio da União.

\section{Mapa 1: Localização do Alto Curso do Rio Uberabinha, Uberlândia, MG}

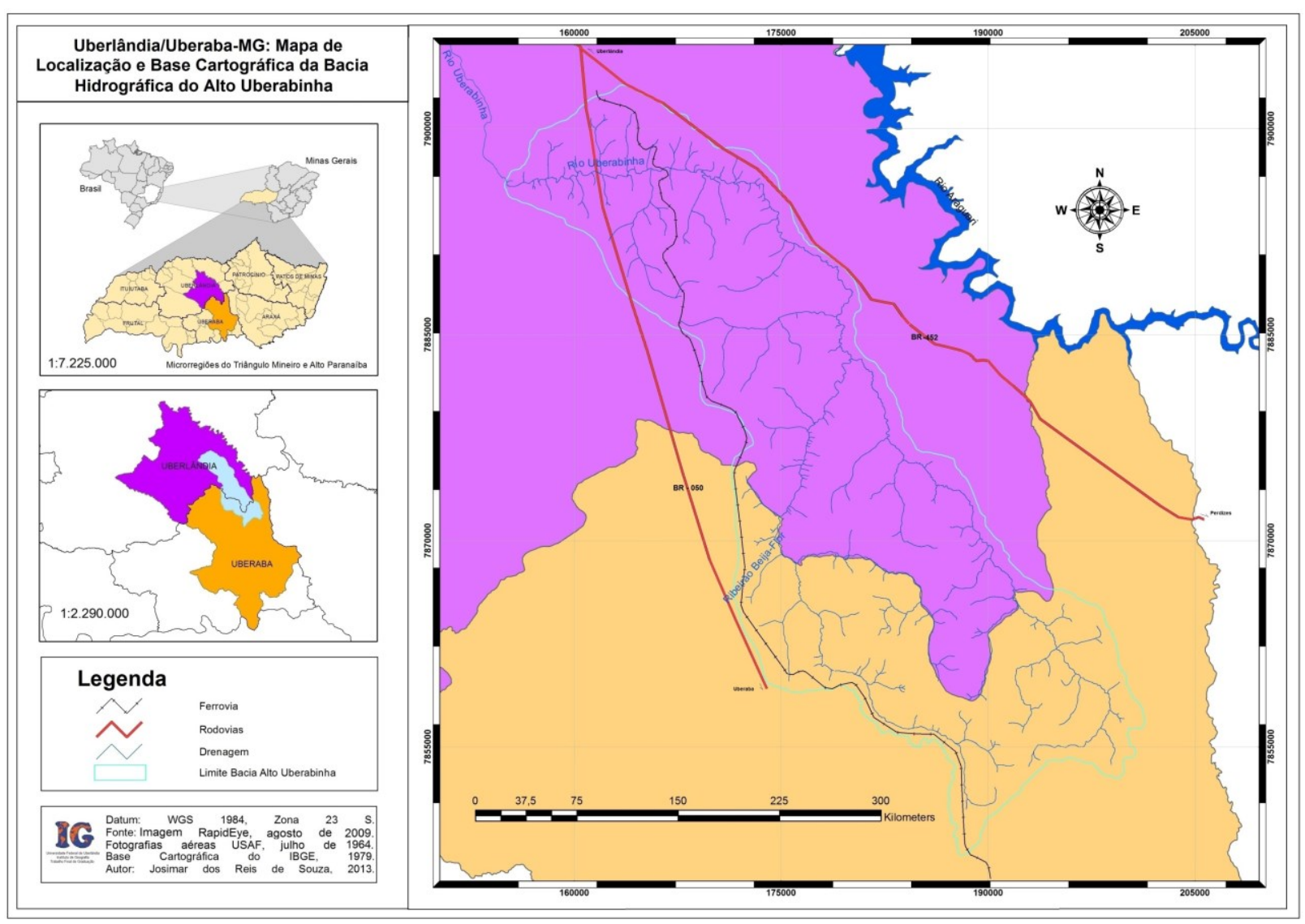

Autor: SOUZA, 2013.

Os territórios drenados do Alto Uberabinha e seus afluentes apresentam trechos de áreas úmidas e topografias embaciadas, com acúmulo de água por 
afloramento do lençol, escoamento sub-superficial e das precipitações pluviais. Tratase de sistemas de drenagem associados às áreas altas de interflúvios de topos planos.

\section{Fases do mapeamento}

Para a elaboração da base cartográfica da área de estudo foram necessárias 7 cartas topográficas na escala 1:50000. A rede de drenagem e o limite da bacia hidrográfica foram produzidos através da digitalização das cartas topográficas no software ArcGIS, versão 10.1. O limite da bacia foi delineado pela observação das curvas de nível e dos pontos cotados das cartas topográficas.

Para o mapeamento do ano de 1964 foram utilizadas as fotografias aéreas de 1964 do USAF/IBC-GERCA (Instituto Brasileiro de Café), na escala de 1:60.000. Foram utilizadas 64 fotografias aéreas já disponibilizadas em formato digital. O registro da imagem foi feito com a utilização do software SPRING 9.8. Utilizando-se da função registro de imagem, fez-se a correção geométrica da imagem, tomando-se no mínimo 25 pontos de controle e um polinômio de $2^{\circ}$ grau. Os pontos de controle foram obtidos da base cartográfica no formato Digital, escala 1:50.000. O erro quadrático médio do registro obtido foi de 6 metros. A imagem georreferenciada foi exportada em formato TIFF e importadas no software ArcGIS para o mapeamento e análise. No ambiente ArcGIS foi gerado o mosaico das fotografias aéreas, resultando em um arquivo no formato raster.

A identificação das áreas úmidas (em 1964 e 2009) seguiram a metodologia de Novo (2008) através da chave de interpretação apresentada no quadro 1. 
Quadro 1: Características das imagens avaliadas no processo de análise visual

\begin{tabular}{|c|l|}
\hline \multicolumn{2}{|c|}{ Características das imagens avaliadas no processo de análise visual } \\
\hline Características da Imagem & \multicolumn{1}{c|}{ Definição } \\
\hline Tonalidade/Cor & $\begin{array}{l}\text { Representa o registro da radiação que foi refletida ou emitida pelos objetos da } \\
\text { superfície. Tonalidades claras estão associadas a área de elevada radiância, emitância } \\
\text { ou retroespalhamento em imagens de sensores ópticos e termais e ativos de micro- } \\
\text { ondas, respectivamente. }\end{array}$ \\
\hline Textura & $\begin{array}{l}\text { A textura de imagem representa a freqüência de mudanças tonais por unidade de área } \\
\text { dentro de uma dada região. A textura da imagem depende da resolução espacial do } \\
\text { sistema, do processo de imageamento e da escala da imagem utilizada. }\end{array}$ \\
\hline Padrão & $\begin{array}{l}\text { O padrão define o arranjo espacial dos objetos na cena. O significado do padrão } \\
\text { também depende do tipo de imagens analisadas, de sua escala e sua resolução } \\
\text { espacial. }\end{array}$ \\
\hline Localização & $\begin{array}{l}\text { A localização representa a posição relativa do objeto ou feição dentro da cena. } \\
\text { Representa a configuração espacial do objeto. Esta forma pode ser observada em } \\
\text { duas dimensões em imagens que não possuem o atributo de estereoscopia, ou em três } \\
\text { dimensões em imagens estereoscópicas. }\end{array}$ \\
\hline Forma & $\begin{array}{l}\text { A sombra dos objetos pode ser utilizada como fonte de informação sobre limites de } \\
\text { unidades geológicas, dimensões relativas de escaras, árvores. O significado das } \\
\text { sombras também é afetado pelo tipo de sensor utilizado, pela resolução espacial do } \\
\text { sensor e pela escala da imagem. }\end{array}$ \\
\hline Tamanho & $\begin{array}{l}\text { O tamanho dos objetos é função da resolução do sistema e da escala das imagens. O } \\
\text { tamanho do objeto pode ajudar em sua identificação. }\end{array}$ \\
\hline
\end{tabular}

Fonte: NOVO, 2008, p. 307. Org.: REIS, 2012.

\section{RESULTADOS}

\section{As áreas úmidas do Alto Curso do Uberabinha em 1964}

A década que compreende o ano do mapeamento (1964) pode ser considerada como período de transição da ocupação do Cerrado, seja por grandes áreas bem preservadas, como também outras áreas iniciando seu processo de intensa ocupação. Pode-se afirmar, portanto que, mesmo áreas que nesse período ainda não estavam sendo utilizada de fato, já estavam inseridas no planejamento econômico, ou seja, já faziam parte da dinâmica do capital e futuramente seriam incorporadas aos grandes empreendimentos agropecuários.

Cabe ainda ressaltar que no período pré-1964, a estrutura fundiária era apontada como causadora da baixa produtividade da agricultura brasileira, daí a questão da reforma agrária ser evidenciada nos últimos governos civis da época. Com - Governo Militar os processos tradicionais e as técnicas de uso da terra passaram a ser vistos como causadores do atraso agrícola do país. Assim, a política agrícola do governo militar veio ao encontro da necessidade de criar mecanismos para 
modernizar o latifúndio com vistas a superar as contradições entre a baixa produtividade agrícola e o discurso oficial desenvolvimentista (SCHNEIDER, 1996).

Através do exposto foi importante mapear a espacialização das áreas úmidas no Alto Curso do Uberabinha no ano de 1964. Ano marcado por início de profundas transformações no processo de ocupação do Cerrado, mas que na área estudada ainda apresentava o antigo modelo de ocupação, propiciando assim identificar as áreas úmidas bem preservadas e com pouca alteração pelos usos antrópicos.

O gráfico 1 apresenta a relação das áreas de hidromorfia pela área total da bacia hidrográfica estudada, obtida através do mapeamento. A relação área úmida/área total da bacia aponta que as áreas úmidas em 1964 ocupavam cerca de $33 \%$ da área total da bacia, representando 280,2 km². Essa informação reafirma a importância das áreas hidromórficas na composição da bacia hidrográfica, como também de toda a área da Chapada do Oeste Mineiro e demais ecossistemas no Cerrado com o mesmo tipo de configuração, tendo estreita relação com o lençol freático e extrema importância para a biota.

Gráfico 1: Áreas Úmidas em 1964: relação área/área total da bacia

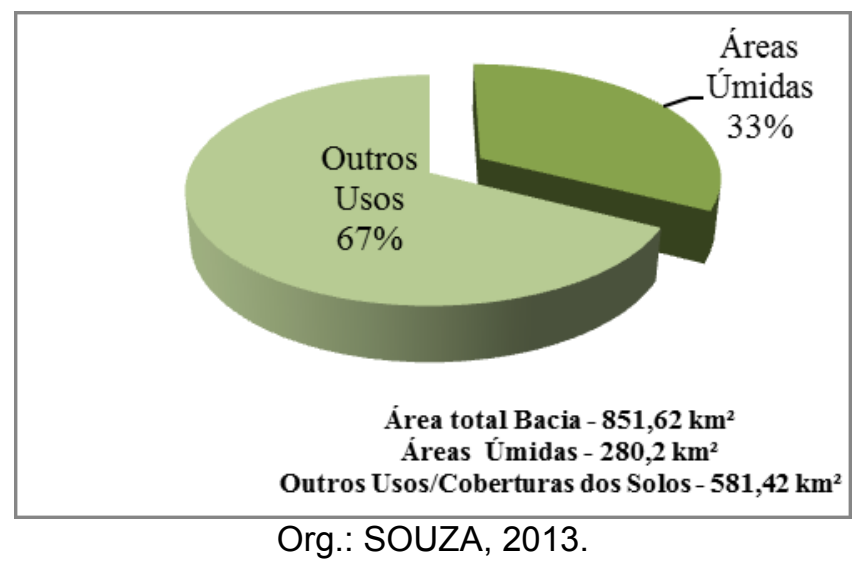

O mapeamento propiciou identificar as áreas com solos de característica hidromórfica em seu estado mais próximo ao original (com pouca alteração antrópica). Essa afirmação se dá pela impossibilidade de fazer esse tipo de análise antes de 1964, pois não existem fotografias aéreas de período anterior, sendo o resultado o 
mais próximo possível da configuração original do sistema hidromórfico da bacia hidrográfica.

Em relação às outras coberturas dos solos no período de 1964, estudos realizados por Schneider (1996) mostram que na área havia 62,37\% de áreas cobertas por Cerrado; 33,7\% por hidromorfia; 1,95\% de manchas esparsas de mata e apenas $1,98 \%$ da área ocupada por ações antrópicas. Os resultados da pesquisa realizado por Schneider (1996), possibilitou o (re)conhecimento de como as áreas do Cerrado, que antes da ocupação eram pouco utilizadas e bem preservadas. Nesse período, o processo de trabalho rural era arraigado ao ambiente natural. A pouca pecuária existente dependia fortemente das gramíneas nativas e os produtos agrícolas cultivados eram basicamente destinados a subsistência (ABREU, 1994).

As condições ambientais dadas pelo relevo, pela fertilidade dos solos, distribuição das chuvas e cobertura vegetal desempenhavam o mais alto grau de influência nesse modelo tradicional agrícola, restringindo ou favorecendo as atividades produtivas. Dessa forma, o modelo agrícola tradicional era um sistema de produção altamente equilibrado do ponto de vista ambiental, onde as diversas espécies animais e vegetais tinham relações de harmonia e complementaridade (SCHNEIDER,1996).

\section{Principais acontecimentos e ações do Estado entre 1964 e 2009}

O esforço governamental para aumentar a produção agrícola de mercado e promover a sua modernização, levou a implementação de planos oficiais de desenvolvimento nas áreas de Cerrado, entre as décadas de 1960 e 1970. Essas políticas se traduziram no estímulo oficial à difusão do uso de insumos modernos, crédito com juros subsidiados para a compra de máquinas agrícolas, fertilizantes, obras de eletrificação rural, construção de açudes e irrigação (PÊSSOA, 1988).

Um dos programas que mereceu destaque foi o POLOCENTRO (Programa de Desenvolvimento dos Cerrados), criado em 1975 para incentivar e apoiar a ocupação das áreas de Cerrado da região Centro-Oeste brasileira. Essa incorporação 
envolvia os estados de Minas Gerais, Goiás, Mato Grosso e Mato Grosso do Sul, com áreas de 3,7 milhões de hectares, sendo 1,8 milhões com lavouras, 1,2 milhões com pecuária e 0,7 milhões com reflorestamentos. Em Minas Gerais o Programa POLOCENTRO abrangeu a Mesorregião do Triângulo Mineiro e Alto Paranaíba, Alto e Médio São Francisco e Vão do Paracatu (FERREIRA, 2006). De acordo com Schneider (1996), o POLOCENTRO sem dúvida resultou na modificação do padrão de uso agrícola da bacia hidrográfica do Uberabinha, principalmente nas áreas que envolvem essa pesquisa, por sua característica aplainada.

A partir do processo de modernização da agricultura brasileira, no final da década de 1970, a chapada do Oeste Mineiro se inseriu definitivamente no modelo do agronegócio de exportação. Isso se deu pela topografia plana que facilitava o emprego de novos maquinários, também pelas técnicas de correção dos solos e ainda pela exploração das jazidas de calcário nas áreas de borda da chapada, a partir de 1975. Os atrativos oferecidos pelo POLOCENTRO para o plantio de soja fizeram com que na década de 1980 houvesse a ampliação das áreas de cultivo de soja. Na década de 1990 as áreas de plantio de Eucalipto (cultivados desde a década de 1970), começaram a sofrer processo de erradicação, para a ampliação das áreas de plantio de soja. Nos anos 2000 é possível afirmar que a bacia atingiu sua quase total utilização, voltada aos agronegócios, e nas poucas áreas preservadas existentes são comumente encontrados avanços de agricultura e outros usos sobre áreas úmidas, inclusive com presença de drenos.

\section{As áreas úmidas do Alto Curso do Uberabinha em 2009}

O Gráfico 2 apresenta a relação das áreas de hidromorfia pela área total da bacia estudada, a partir do mapeamento das áreas úmidas no ano de 2009. Em 2009 as áreas úmidas ocupavam $20 \%$ da área total da bacia, representando 173,50 km². 


\section{Gráfico 2: Áreas Úmidas em 2009: relação área de Hidromorfia/área total da bacia}

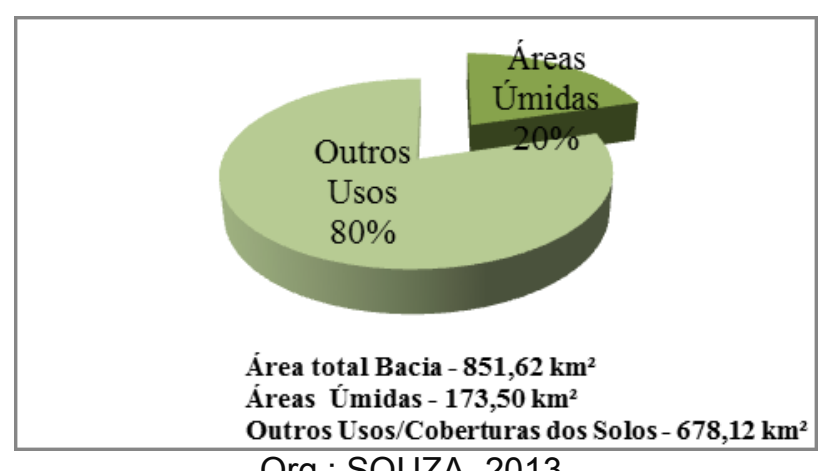

Org.: SOUZA, 2013.

O mapeamento das áreas úmidas em 2009 possibilitou a identificação das áreas preservadas mesmo com o intenso processo de ocupação do Cerrado. Estudos realizados por Sano et al. (2001) estimam que a taxa de expansão da atividade agropecuária sobre áreas nativas de Cerrado é de $3 \%$ ao ano. As previsões mais otimistas apontam que se mantida a taxa atual de desmatamento, em 2030, as áreas de ocorrência do bioma Cerrado, serão restritas as áreas de proteção. Em consequência do desmatamento e da fragmentação, a vegetação do Cerrado se apresenta na forma de grande mosaico de fitofisionomias remanescentes, que englobam as áreas úmidas. Estas comumente conservam sua característica própria e são envoltas por uma matriz alterada, que as condiciona a distúrbios antrópicos de diversos tipos (EMBRAPA, 2008).

As outras coberturas dos solos para o ano de 2009 foram mapeadas por Oliveira (2013). Os resultados apontam que em 2009 na área de estudo havia 64\% de áreas utilizadas para agricultura, $20 \%$ de áreas úmidas, $12 \%$ da área utilizada para silvicultura, 3,5\% de pastagem, somente 0,3\% de áreas remanescentes de Cerrado, $0,1 \%$ de áreas com presença de mineração e 0,1\% de áreas de lagos artificiais. Os resultados demonstram o alto grau de ocupação e utilização da bacia, restringindo as áreas preservadas a menos de um quarto do total. A presença de áreas de mineração, extensas áreas contínuas de agricultura e grande número de lagos artificiais, apontam problemas ambientais, seja pela grande demanda de água para a 
agricultura irrigada, como também pela impossibilidade de recuperação de áreas que passaram por processos de extração mineral. Além disso, problemas sociais ligados aos grandes latifúndios, agravam os conflitos pelo uso e ocupação das terras e dos recursos hídricos.

\section{A Regressão de Áreas Úmidas entre 1964 e 2009}

A mapa 2 apresenta o resultado da Regressão de Áreas Úmidas na bacia do Alto Curso do Uberabinha entre os anos de 1964 e 2009, a partir da sobreposição dos mapeamentos realizados anteriormente.

Mapa 2: Regressão de Áreas Úmidas do Alto Curso do Uberabinha - anos 1964 e 2009

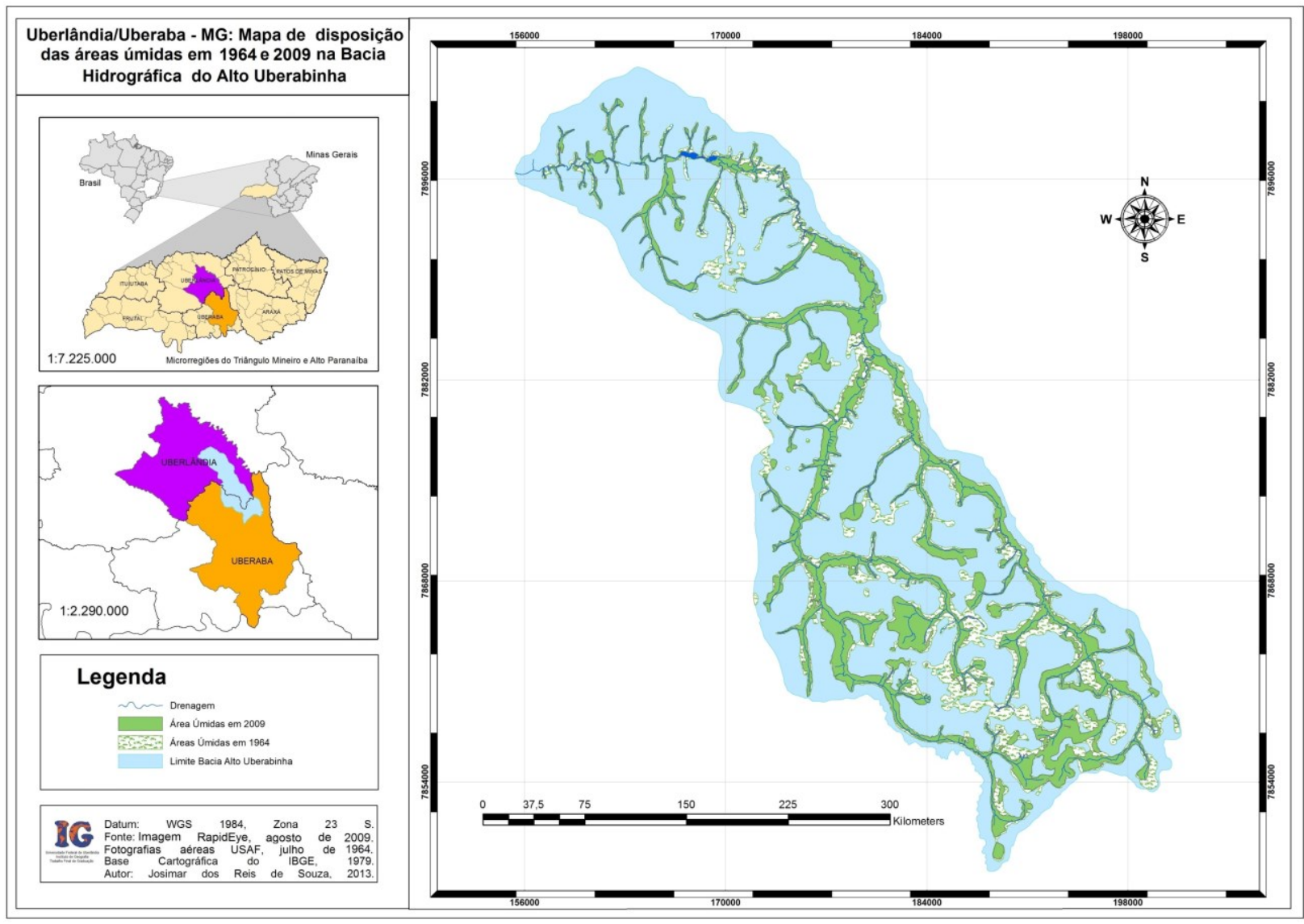

Autor: SOUZA, 2013. 
Os resultados demonstram que extensas áreas originalmente constituídas de áreas úmidas foram substituídas por outros usos. As áreas úmidas em 1964 ocupavam 280,2 km² e passaram a ocupar em 2009 173,5 km², ou seja, uma redução de $38,08 \%$. O gráfico 3 apresenta essa diminuição das áreas úmidas, como também o aumento das áreas destinadas a outros usos.

Gráfico 3: Regressão de Áreas Úmidas/aumento de áreas de outros usos de 1964/2009.

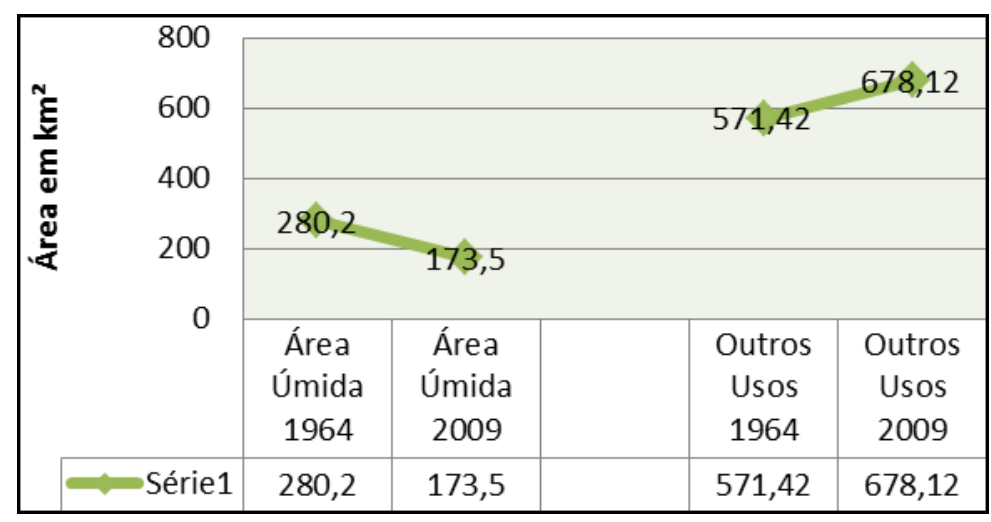

Org.: SOUZA, 2013.

Em relação aos outros usos do solo em ambos os períodos é possível fazer uma comparação da mensuração dos usos dos solos (gráfico 4) realizados por Schneider (1996) e Oliveira (2009). No ano de 1964 as áreas preservadas, incluindo as áreas de vegetação natural, hidromorfia e manchas esparsas de mata somavam $874,77 \mathrm{~km}^{2}$, ou seja, $98,02 \%$ da bacia permaneciam preservadas e apenas $1,8 \%$ se configuravam como áreas de uso antrópico. Para o ano de 2009, as áreas de hidromorfia e manchas esparsas de mata somavam apenas $172,7 \mathrm{~km}^{2}$, se constituindo apenas $20,30 \%$ da área da bacia preservada. Nota-se, portanto uma redução das áreas naturais em $77,72 \%$. 
Gráfico 4: Comparação Uso dos Solos 1964 - 2009.

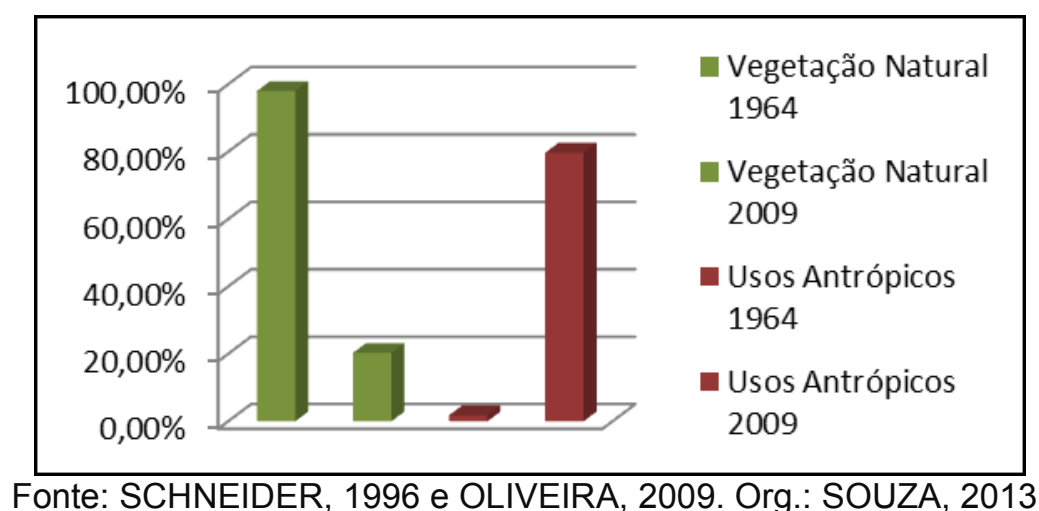

A comparação das fotografias aéreas de 1964 e as imagens de satélite de 2009 demonstra a grande alteração sofrida no ambiente natural. A figura 1 apresenta o exemplo da nascente do Córrego Rancharia, que compõe a bacia. É possível perceber a grande alteração sofrida pelo uso dos solos para agricultura e também silvicultura, que acaba por praticamente isolar a área de Murundus (Covoal) existente.

Figura 1: Nascente do Córrego Rancharia - anos 1964 e 2009

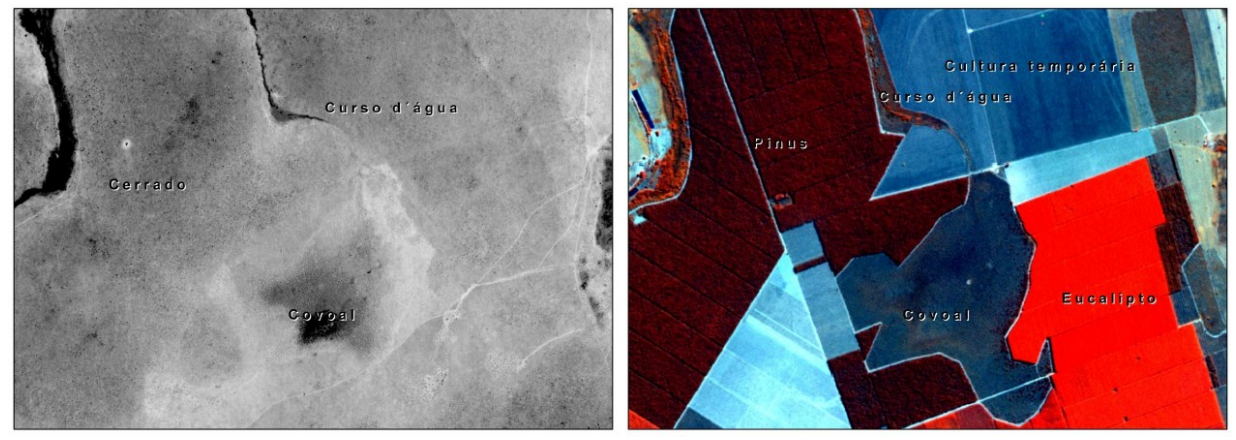

Fonte: BORGES, 2011.

A figura 2 apresenta a divisa da bacia hidrográfica dos Ribeirões Beija-Flor e Bom Jardim. É possível perceber que áreas úmidas preservadas em 1964 foram incorporadas a atividade agrícola, mas mantendo sua característica hidromórfica (diferenças de coloração indicam a presença de água). 
Figura 2: Limite Bacias dos Ribeirões Bom Jardim e Beija Flor - anos 1964 e 2009

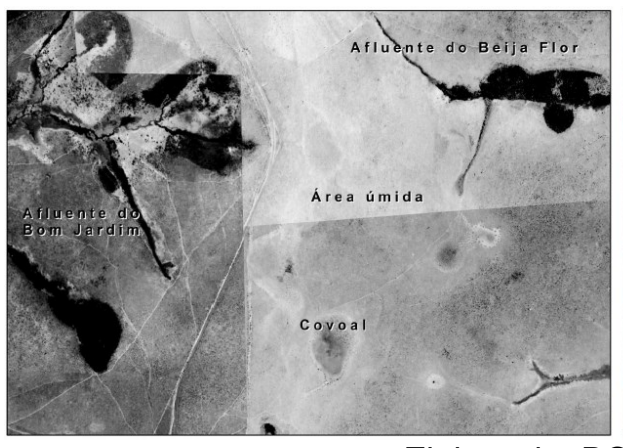

Elaborado: BORGES, 2011.

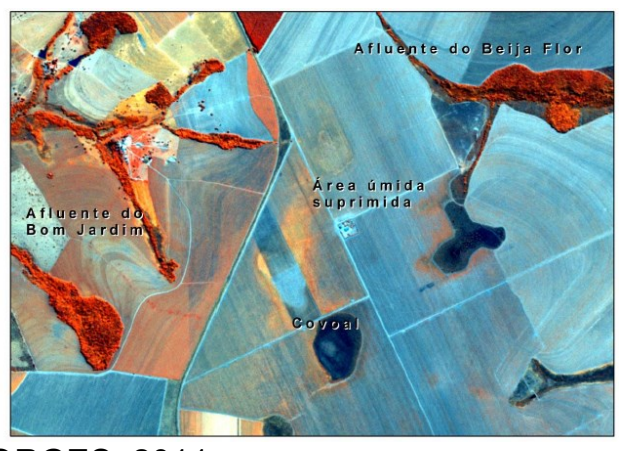

1

$\mathrm{Na}$ área de estudo, ainda são encontrados drenos, que visam principalmente drenas as áreas úmidas que se encontram "ilhadas" em meio às monoculturas, como os casos apresentados nas figuras 1 e 2 . Os drenos são comumente encontrados também em outras partes do Cerrado. Em estudos realizados no interior do Mato Grosso, Castro Júnior (2002), afirma que as tentativas de utilização das áreas úmidas inicialmente não foram bem sucedidas, porque o lento escoamento das águas cria lâminas de água superficial, que se aquecem com 0 sol e favorecem 0 desenvolvimento de fauna limnológica, que provoca doenças fúngicas. Além disso, nessas áreas não era possível a operacionalização do solo por meio de tratores e colheitadeiras. Tais dificuldades foram resolvidas com o rebaixamento do nível freático, por meio da escavação de rede de valetas que promovem o escoamento das águas direcionando-as ao canal fluvial. Desta forma, as águas retidas pelo solo durante as chuvas intensas, que normalmente demandariam 2 a 5 dias para escoar para o canal fluvial, por meio da rede de valetas escavadas, levam apenas algumas horas, eliminando assim, os solos supersaturados, com lâmina d'água na superfície do terreno. Esta técnica ainda vem sendo amplamente adotada nos planaltos do Cerrado, sendo difícil encontrar áreas úmidas totalmente intactas (CASTRO JÚNIOR, 2002). 


\section{CONCLUSÕES}

Os resultados da comparação entre os usos dos solos reafirmam a intensidade dos processos de substituição da área natural pela agricultura em grande escala. Nesse sentido pode-se afirmar que as áreas ainda hoje preservadas na bacia hidrográfica só continuam a existir pela presença de hidromorfia, que dificultou durante as últimas décadas o avanço das áreas agrícolas sobre as áreas úmidas. As áreas úmidas que permanecem, tem sua borda definida até o ponto em que a agricultura consegue avançar, fazendo com que estas formas sejam retilíneas, alterando completamente o formato original das áreas úmidas.

Observa-se, portanto, que as áreas preservadas na bacia hidrográfica estudada, ainda representam cerca de $20 \%$, por se tratarem de áreas úmidas, que mesmo com leis de proteção, por se tratarem de áreas de Preservação Permanente (APP), sofrem pressão das monoculturas, principalmente nas áreas de contato agricultura-vereda e muitas vezes continuam a ser drenadas em prol da expansão das áreas agrícolas.

Por se tratarem de Áreas de Preservação Permanente (APP), as áreas úmidas da Bacia Hidrográfica do Rio Uberabinha merecem especial atenção da fiscalização e órgãos de proteção, por constituírem como a principal rede de drenagem para o abastecimento de água das áreas urbanizadas de Uberlândia, como também importante fonte de irrigação de extensas áreas de agricultura, e, sobretudo, por serem habitat e refúgio de elevado número de espécies de animais e vegetação, que somente vivem nestes ambientes.

\section{REFERÊNCIAS}

ABREU, A. M. Catanduva, um problema no norte de Minas. Viçosa: UFV, 1981. 80 p.

ÁVIDOS, M. F. D.; FERREIRA, L. T. Frutos dos Cerrados: preservação gera muitos frutos. Goiânia: UFG, 2007. 125 p.

BOAVENTURA, R. S. Vereda berço das águas. Belo Horizonte: Ecodinâmica, 2007. 264 p.

BORGES, F. A. Caracterização temporal das áreas úmidas e de preservação permanente da porção de Alto e Médio curso da Bacia Hidrográfica do Rio Uberabinha - MG com a aplicação de técnicas de 
geoprocessamento. (Dissertação de Mestrado) - Instituto de Geografia, Universidade Federal de Uberlândia, Uberlândia, 2012. 135 f.

BRITO, J. L. S. Adequação das potencialidades do uso da terra na Bacia do ribeirão Bom Jardim no Triângulo Mineiro (MG): Ensaio de Geoprocessamento. (Tese de Doutorado) - Faculdade de Filosofia, Letras e Ciências Humanas, Universidade de São Paulo. São Paulo: USP, 2001.

CASTRO JÚNIOR, P. R. Dinâmica da Água em Campos de Murundus do Planalto dos Parecis. (Tese de Doutorado) - Faculdade de Filosofia, Letras e Ciências Humanas, Universidade de São Paulo. São Paulo: USP, 2002.

EMBRAPA. Cerrados Ecologia e Flora - Volume 1. Brasília: Embrapa Informação Tecnológica, 2008.

FERREIRA, I. M. Aspectos Ecológicos e paisagísticos das Veredas. In: VI Simpósio Nacional de Geomorfologia/Regional Conference on Geomorfologia, 2006, Goiânia (GO), 2006. v. 1. p. 1-10.

OLIVEIRA, D. A. As áreas de preservação permanente em topo de chapada e a adequação à legislação. (Dissertação de Mestrado) - IG, Universidade Federal de Uberlândia, 2013. 114 f.

REFORD, K.H.; FONSECA, G. A. B. The role of gallery forest in the zoogeography of the cerrados's no volant mammalian fauna. In: Biotropica, n. 18., 1986. p. 117-138.

SANO, E. E.; JESUS, E. T.; BEZERRA, H. S. Uso de um sistema de informação geográfica para quantificação de áreas remanescentes do Cerrado. Planaltina, DF: Embrapa Cerrados, 2001.

SCHNEIDER, M. O. Bacia do Rio Uberabinha: Uso agrícola do solo e meio ambiente. (Tese de Doutorado), Instituto de Geociências, Universidade de São Paulo, São Paulo, 1996. 157 f. 